\title{
Evaluation of the U.S. Adherence Questionnaires VERITAS-PRO and VERITAS-PRN for Use in Patients with Hemophilia in the German Healthcare System
}

\author{
Sylvia von Mackensen ${ }^{1} \quad$ Yves Douma $^{2}$ Susan Halimeh ${ }^{2}$ \\ ${ }^{1}$ Department of Medical Psychology, University Medical Centre
Hamburg-Eppendorf, Hamburg, Germany
${ }^{2}$ GZRR - Gerinnungszentrum Rhein-Ruhr, Duisburg, Germany \\ Hämostaseologie 2020;40:621-630. \\ Address for correspondence Sylvia von Mackensen, PhD, Department \\ of Medical Psychology, University Medical Centre Hamburg- \\ Eppendorf, Martinistr. 52, 20246 Hamburg, Germany \\ (e-mail: s.mackensen@uke.de).
}

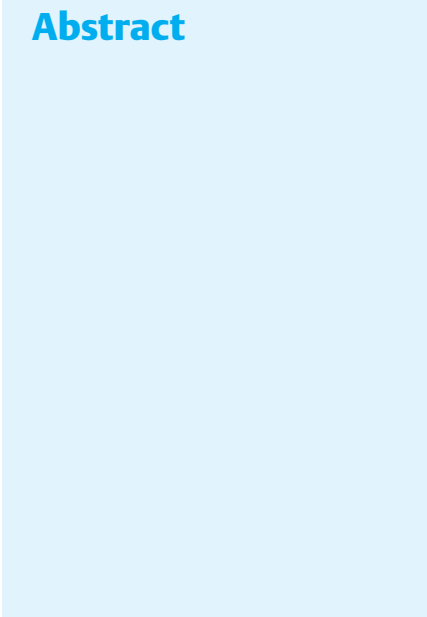

Keywords

- hemophilia

- adherence

- assessment

- VERITAS-PRO

- VERITAS-PRN

\section{Zusammenfassung}

Aim Since the U.S. adherence instruments VERITAS-PRO and VERITAS-PRN were developed in another healthcare system, we assumed that they are not appropriate for the German solidarity healthcare system. This study aims to evaluate the relevance of these instruments for the German healthcare system both by people with hemophilia (PWH) and by healthcare professionals (HCP).

Methods A total of $50 \mathrm{PWH}$ (23 adult hemophilia patients and 27 parents of children with hemophilia) and $25 \mathrm{HCP}$ rated the relevance of the single items of the VERITASPRO and VERITAS-PRN on a 5-point Likert scale. In addition, both groups were asked to make suggestions for additional adherence questions. To investigate the relevance of these instruments, the accordance between the raters' evaluations was determined calculating the content validity index $(\mathrm{CVI})$ and the content validity ratio (CVR) based on the critical values of the CVR ( $\left.\mathrm{CVR}_{\text {critical }}\right)$ to exclude chance and subjectivity.

Results CVI (CVR) calculations revealed three (5) "very important" items for PWH and six (11) items for HCP. Only two (3) "very important" items were evaluated by both groups. Four domains were considered not important by both groups. Six PWH made 14 suggestions and $14 \mathrm{HCP}$ made 24 suggestions for additional adherence questions. Conclusion VERITAS-PRO and VERITAS-PRN have only very limited benefits for the German healthcare system. Since nonadherence has a great impact on the morbidity of $\mathrm{PWH}$ and on the costs for the healthcare system, there is a need for adherence instruments that are adapted to the specific needs of PWH in the German healthcare system.

Ziel Der Umstand, dass die Adhärenz-Messinstrumente VERITAS-PRO und VERITASPRN für das US-amerikanische Gesundheitssystem entwickelt wurden, lässt vermuten, dass sie im solidarisch finanzierten deutschen Gesundheitssystem nur eingeschränkten Nutzen haben. Diese Studie zielt darauf ab, die Relevanz der beiden Instrumente für das deutsche Gesundheitssystem sowohl von Personen mit Hämophilie (PWH) als auch von Angehörigen der Gesundheitsberufe (HCP) evaluieren zu lassen.

Methoden 50 PWH (23 erwachsene Hämophilie-Patienten und 27 Eltern von Kindern mit Hämophilie) und 25 HCP bewerteten die Relevanz der einzelnen VERITAS-PRO und received

June 1, 2020

accepted after revision

August 28, 2020 (c) 2020 Georg Thieme Verlag KG Stuttgart · New York
DOI https://doi.org/

10.1055/a-1249-4645. ISSN 0720-9355. 


\author{
Schlüsselwörter \\ - Hämophilie \\ - Adhärenz \\ - Erfassung \\ - VERITAS-PRO \\ - VERITAS-PRN
}

VERITAS-PRN-Items auf einer 5-Punkt-Likert-Skala. Darüber hinaus wurden beide Gruppen gebeten, Vorschläge für zusätzliche Fragen zur Messung von Adhärenz zu machen. Um die Relevanz dieser Instrumente zu bestimmen, wurde die Übereinstimmung zwischen den Expertenurteilen anhand des Inhaltsvaliditäts-Indexes (CVI) und des Inhaltsvaliditäts-Verhältnisses (CVR) basierend auf den kritischen CVR-Werten $\left(C V R_{\text {critical }}\right)$ berechnet, um somit Zufall und Subjektivität ausschließen zu können.

Ergebnisse CVI (CVR) Berechnungen ergaben drei (5) „sehr wichtige“ Items für PWH und sechs (11) Items für HCP. Nur zwei (3) Items wurden von beiden Gruppen als „sehr wichtig“ bewertet. Vier Domänen wurden von beiden Gruppen als nicht wichtig erachtet. Sechs PWH machten 14 und vierzehn HCP machten 24 Vorschläge für zusätzliche Adhärenz-Fragen.

Konklusion Im deutschen Gesundheitssystem haben der VERITAS-PRO und der VERITAS-PRN nur sehr eingeschränkten Nutzen. Da Nicht-Adhärenz deutlich negative Effekte sowohl auf die Morbidität der PWH als auch auf die Kostenentwicklung im deutschen Gesundheitssystem hat, gibt es einen Bedarf an Adhärenz-Messinstrumenten, die an die spezifischen Bedürfnisse von PWH im deutschen Gesundheitssystem angepasst sind.

\section{Introduction}

The World Health Organization (WHO) defines the term "adherence" as "the extent to which a person's behaviortaking medication, following a diet, and/or executing lifestyle changes, corresponds with agreed recommendations from a healthcare provider." As early as 2003, the WHO emphasized that the terms "adherence" and "compliance" do not describe the same phenomenon: "The main difference is that adherence requires the patient's agreement to the recommendations. We believe that patients should be active partners with health professionals in their own care and that good communication between patient and health professional is a must for an effective clinical practice."1 If, in particular, chronically ill people do not adhere to these health behavior recommendations, or do not adhere to them sufficiently, this accounts for less effectiveness of prescribed therapies and therefore increased burden-with regard to individual health constraints and collective financial burden for the healthcare system. ${ }^{2}$

Adherence/compliance and its counterpart noncompliance are complex phenomena. Vermeire et al suggest to distinguish various forms of noncompliance taking different aspects into consideration: care-seeking aspects (including screening, follow-up, and treatment) $)^{3}$; medication-related aspects, and intention-related aspects where all of the behavioral patterns can be either intentional or unintentional. ${ }^{2}$ For the medication-related aspects, it can be distinguished between primary noncompliance (where a prescription is received, but not taken at a pharmacy) and secondary noncompliance. The latter includes behavioral aspects such as taking an incorrect dose of the medication or at wrong times, forgetting doses of the medication or stopping the treatment earlier. ${ }^{4}$ The adherence of individual patients is multifactorial. Five factors can be distinguished that influence the level of adherence: socioeconomic, therapy, patient, indication, and healthcare system-related factors. ${ }^{1}$

Adherence has recently become of great interest also in hemophilia. In 2014 alone, there were almost 20 publications on this topic according to a counting of Khair ${ }^{5}$; hemophilia treaters now attach greater importance to this topic. $^{6-8}$ In hemophilia patients (PWH [people with hemophilia]), adherence has a major impact on their health state and thus also on the financial burden or relief of the respective healthcare systems in which $\mathrm{PWH}$ are cared for. ${ }^{9}$ In a 2013 study with 80 U.S. adolescents and young adults (AYA) with moderate or severe hemophilia, it could be shown that the higher their adherence was, the less chronic pain the AYA-PWH reported. ${ }^{10}$ In another international study, lower adherence in $110 \mathrm{PWH}$ and caregivers of pediatric PWH were associated with higher numbers of bleeding episodes, lower health status, and more days missed at work and school. ${ }^{11}$ Nonadherence in hemophilia treatment limits the effectiveness of the factor concentrates and contributes to suboptimal avoidance of bleeding and its long-term consequences, especially related to orthopaedic sequelae. ${ }^{7}$ In addition, nonadherence negatively influences the prescribing behavior of hemophilia treaters and can therefore lead to a vicious circle in the relationship between hemophilia treaters and PWH. ${ }^{12}$ Miesbach and Kalnins had identified potential risk factors for nonadherence in 397 hemophilia patients (age range: $0-80$ years) from the German patient organization; they found mainly condition-related, therapy-related, and healthcare system/ healthcare team-related factors. ${ }^{13}$ From the economic perspective of the healthcare system, hemophilia is a relatively expensive disease, even if it belongs to the rare diseases. ${ }^{14,15}$ The prevalence of hemophilia $A$ is estimated at 1 in 5,000 to 10,000 , and that of hemophilia B in 1 in 25,000 to 30,000 male births. ${ }^{16}$ For example, in 2015 the annual 
treatment costs in Germany averaged $€ 319,024$ per patient. ${ }^{17}$ Due to these high treatment costs, the detection of nonadherence in PWH is important. Moreover, the evaluation of adherence supports the evaluation of possible adherence barriers and can help PWH to overcome these barriers. 6,18

\section{Measuring Adherence}

A distinction is made between direct and indirect methods when measuring adherence. With direct measurement methods, the plasma concentration is measured; with indirect measurement methods, the behavior that contributes to the change in the plasma concentration is examined. The direct measurement methods are also referred to as "therapeutic drug monitoring"; the indirect measurement methods include pill counting, patient diaries, patient interviews, medication profile, and electronic observation systems. ${ }^{1,19}$

The indirect methods can be differentiated according to objective and subjective methods. ${ }^{20}$ The adherence measurement by healthcare professionals (HCP) usually consists of the calculation of the ratio of the prescribed and used factor concentrate based on the treatment diaries kept electronically or in paper form by patients. ${ }^{21}$ Standardized and validated questionnaires are required for the adequate assessment of self-reported adherence to hemophilia therapy. ${ }^{22}$

When we started with this project, no hemophilia-specific adherence measure was available that fits the German healthcare system financed by solidarity. The only validated instruments were developed by Duncan et al in the United States: The "Validated Hemophilia Regimen Treatment Adherence Scale Prophylaxis" (VERITAS-PRO) questionnaire assesses the adherence of PWH with prophylaxis treatment, ${ }^{23}$ whereas the "Validated Hemophilia Regimen Treatment Adherence Scale On-Demand" (VERITAS-PRN) questionnaire assesses the adherence of PWH with on-demand treatment. ${ }^{24}$

Although the VERITAS questionnaires were used in several observational and clinical studies, ${ }^{10,25,26}$ and are available in more than 30 languages, only few articles regarding their psychometric validation and cross-cultural adaptation in other languages then the original U.S. English language have been published so far (VERITAS-PRO: Dutch, ${ }^{27}$ Spanish, ${ }^{28}$ Portuguese/Brazil versions ${ }^{29}$; VERITAS-PRO and VERITAS-PRN: Canadian-French version ${ }^{30}$ ). However, these authors reported some critical points related to their cross-cultural adaptation of the VERITAS-PRO which can be categorized into (1) different understandings of linguistic concepts used in the questionnaires, ${ }^{30}(2)$ relevance of the single items across different healthcare systems (e.g., different economical adherence incentives), and (3) problems related to the internal consistency. ${ }^{27-30}$

Due to these described critical points and intrigued by the definition of the WHO that five factors, among them healthcare system-related factors, determine the level of adherence, ${ }^{31}$ we wanted to examine whether or to what extent these U.S. instruments are considered useful and relevant by
PWH and HCP for the assessment of treatment adherence in the context of the German healthcare system.

\section{Methods}

The project consisted of two phases: evaluation of the VERITAS-PRO and VERITAS-PRN from the perspectives of PWH and HCP.

\section{Procedures}

In the first phase, $50 \mathrm{PWH}$ ( 23 adults and 27 parents of children with hemophilia) from the Duisburg Haemophilia Treatment Centre (HTC), the Coagulation Centre Rhein-Ruhr (GZRR), were asked to evaluate the relevance of the VERITAS-PRO and the VERITAS-PRN during a patient meeting in 2015. PWH evaluated the relevance of the respective adherence questionnaire for German PWH corresponding to their current treatment regimen. They were also able to make suggestions for additional adherence questions. Few clinical data concerning type and severity of hemophilia as well as the treatment regimen were asked to $\mathrm{PWH}$ to stratify the cohort to the respective groups (prophylaxis, on-demand).

In the second phase, a total of 27 evaluation questionnaires were sent to 12 HTC in Germany in 2017, and the HCP contacted were asked to fill in and return the evaluation questionnaires. ${ }^{32}$ Unlike PWH, HCP were supposed to assess both the items of the VERITAS-PRO and the VERITAS-PRN. Like the PWH, the HCP had the opportunity to formulate suggestions for questions of an adherence questionnaire.

PWH and HCP were informed about the aim and the method of the study. They were advised that by submitting their completed evaluation form, they consent that their answers will be analyzed and published for scientific purposes. They were also notified about the confidentiality of their responses and anonymity in data elaboration for this publication. Hence, no ethical approval had to be obtained.

\section{Scale Description of the VERITAS-PRO and VERITAS- PRN}

The VERITAS-PRO and VERITAS-PRN are available as selfreports and parent reports. Both questionnaires have 24 items in six domains. In the VERITAS-PRO, the six domains are as follows: "Timing," "Dosing," "Planning," "Remembering," "Skipping," and "Communicating" ${ }^{23}$; in the VERITASPRN, they are as follows: "Treating," "Timing," "Dosing," "Planning," "Remembering," and "Communicating."24 Both questionnaires use 5-point Likert scales, ranging from 1 to 5 (never or $0 \%$ of the time, rarely or $25 \%$ of the time, sometimes or at least $50 \%$ of the time, often or at least $75 \%$ of the time, and always or $100 \%$ of the time), with total scores ranging from 24 (most adherent) to 120 (least adherent).

\section{Calculation of the Content Validity of the VERITAS-PRO and VERITAS-PRN}

Multiple methods for content validity (CV) testing exist and are used to assess the agreement among raters regarding 
how pertinent each item is in relation to the objective of its measurement. Gilbert and Prion ${ }^{33}$ recommended that for calculating the $\mathrm{CV}$ of an instrument, the Content Evaluation Panel should be composed of persons who are experts about the domain being studied and that a panel of 5 to 10 experts is preferable to accomplish that.

PWH and HCP were asked to evaluate each item of the VERITAS-PRO/-PRN in terms of relevance for the German healthcare system on a 5 -point Likert scale ( $1=$ very important, 2 =important, $3=$ neither important nor unimportant, $4=$ not important, and $5=$ not important at all). All three groups were evaluated separately, the two patient subgroups rated the VERITAS questionnaire according to their treatment regimen (prophylaxis: VERITAS-PRO; on-demand: VERITAS-PRN) and the HCP group (rated both VERITAS questionnaires).

The CV of the VERITAS-PRO/-PRN was calculated by determining the content validity index $(\mathrm{CVI})^{34}$ and the content validity ratio (CVR). ${ }^{35}$ The CVI is the most frequently used method in instrument development and can be computed for each item as the number of experts evaluating an item as "very relevant" divided by the total number of experts. CVI values range from 0 to 1 ; values $\geq 0.8$ indicate the appropriateness of $\mathrm{CV} .{ }^{36}$

$$
\mathrm{CVI}=\frac{n e}{N}
$$

$\mathrm{CVI}=$ content validity index

ne $=$ number of raters indicating an item as "essential"

$\mathrm{N}=$ total number of raters

Since the CVI is criticized to be an index of inter-rater agreement which can be inflated by chance factors, ${ }^{36}$ we calculated in addition the CVR, which was defined by Lawshe as a linear transformation of a proportional level of agreement on how many "experts" within a panel rate an item "essential." 35 CVR values range from +1 to -1 ; positive values indicate that at least half the experts rated the item as essential.

$$
\mathrm{CVR}=\frac{n e-(N / 2)}{(N / 2)}
$$

$\mathrm{CVR}=$ content validity ratio

ne $=$ number of raters indicating an item as "essential"

$\mathrm{N}=$ total number of raters

To exclude chance and subjectivity, Ayre and Scally calculated critical values of the CVR $\left(\mathrm{CVR}_{\text {critical }}\right)$ for group sizes between 5 and 40 raters which are greater than the random value. ${ }^{37} \mathrm{CVR}_{\text {critical }}$ values are inversely proportional to the group size. Based on the simplified table of $\mathrm{CVR}_{\text {critical }}$ related to the number of experts required to agree an item essential, ${ }^{37}$ the $\mathrm{CVR}_{\text {critical }}$ for PWH with prophylaxis $(n=36)$ is 0.333 , for PWH with on-demand treatment $(n=14)$ is 0.571 and for HCP $(n=25)$ is 0.440 (see - Table 1 ).

All statistical analyses were conducted using the SPSS program version 24 (SPSS Inc. Chicago, Illinois, United States). Descriptive data are shown as frequency distribution in percent or as mean \pm standard deviation $(\mathrm{M} \pm \mathrm{SD}$ ), median, and range according to distribution.
Table 1 Simplified table of $\mathrm{CVR}_{\text {critical }}$ including number of experts required to agree an item essential

\begin{tabular}{|l|l|l|l|}
\hline $\begin{array}{l}\text { Panel } \\
\text { size }\end{array}$ & $\begin{array}{l}N_{\text {critical (minimum }} \\
\text { number of experts } \\
\text { required to agree an } \\
\text { item essential for } \\
\text { inclusion) }\end{array}$ & $\begin{array}{l}\text { Proportion } \\
\text { agreeing } \\
\text { essential }\end{array}$ & CVR $_{\text {critical }}$ \\
\hline 10 & 9 & 0.900 & 0.800 \\
\hline 11 & 9 & 0.818 & 0.636 \\
\hline 12 & 10 & 0.833 & 0.667 \\
\hline 13 & 10 & 0.769 & 0.538 \\
\hline $14^{\text {a }}$ & 11 & 0.786 & 0.571 \\
\hline $25^{\mathrm{b}}$ & 18 & 0.720 & 0.440 \\
\hline 26 & 18 & 0.692 & 0.385 \\
\hline 27 & 19 & 0.704 & 0.407 \\
\hline 28 & 19 & 0.679 & 0.357 \\
\hline 29 & 20 & 0.690 & 0.379 \\
\hline 30 & 20 & 0.667 & 0.333 \\
\hline 31 & 21 & 0.677 & 0.355 \\
\hline 32 & 22 & 0.688 & 0.375 \\
\hline 33 & 22 & 0.667 & 0.333 \\
\hline 34 & 23 & 0.676 & 0.353 \\
\hline 35 & 23 & 0.657 & 0.314 \\
\hline $36^{\mathrm{c}}$ & 24 & 0.667 & 0.333 \\
\hline & & & \\
\hline
\end{tabular}

Abbreviations: $\mathrm{CVR}_{\text {critical }}$, critical value of content validity ratio; $\mathrm{HCP}$, healthcare professionals; PWH, people with hemophilia.

Source: Adapted from Ayre and Scally. ${ }^{37}$

${ }^{a}$ Number of PWH on on-demand $(n=14)$.

${ }^{\mathrm{b}}$ Number of HCPs $(n=25)$.

${ }^{\mathrm{C}}$ Number of PWH on propyhlaxis $(n=36)$.

\section{Results}

In the following, we will describe the evaluations separately for the two subgroups of PWH and then for the HCP group. Finally, we will compare the findings across the three groups.

\section{Demographic and Clinical Data of the PWH}

A total of $50 \mathrm{PWH}$ (average age: $35.78 \pm 11.0$ years) initially assessed the VERITAS-PRO or VERITAS-PRN according to their current treatment or that of their hemophilic child. Of the PWH, 23 were adult hemophilia patients (46\%) and 27 were parents of hemophilic children (54\%), the majority of who were mothers $(n=25)$. Most PWH had hemophilia A (78\%), with a severe form (62\%); $74.1 \%$ of children received prophylactic treatment compared with $47.8 \%$ of adults (see -Table 2).

\section{Demographic Data of the Healthcare Professionals}

Twenty-five out of 27 HCP returned the completed questionnaires (92.6\%): 16 (64\%) were physicians (internist, pediatrician), 6 (24\%) were nurses, and $3(12 \%)$ were others (study nurse, hemostaseology assistant, psychologists). 
Table 2 Clinical data of PWH $(n=50)$

\begin{tabular}{|c|c|c|c|c|c|c|c|}
\hline \multicolumn{2}{|l|}{ Clinical data } & \multicolumn{2}{|c|}{$\begin{array}{l}\text { All participants } \\
N=50\end{array}$} & \multicolumn{2}{|c|}{$\begin{array}{l}\text { Adults } \\
N=23\end{array}$} & \multicolumn{2}{|c|}{$\begin{array}{l}\text { Children } \\
N=27\end{array}$} \\
\hline & & $N$ & $\%$ & $N$ & $\%$ & $N$ & $\%$ \\
\hline \multirow[t]{3}{*}{ Bleeding disorders } & Hemophilia A & 39 & 78.0 & 18 & 36.0 & 21 & 42.0 \\
\hline & Hemophilia B & 7 & 14.0 & 4 & 8.0 & 3 & 6.0 \\
\hline & VWD type 3 & 4 & 8.0 & 1 & 2.0 & 3 & 6.0 \\
\hline \multirow[t]{3}{*}{ Severity } & Mild & 16 & 32.0 & 14 & 28.0 & 2 & 4.0 \\
\hline & Moderate & 3 & 6.0 & 0 & 0 & 3 & 6.0 \\
\hline & Severe & 31 & 62.0 & 9 & 18.0 & 22 & 44.0 \\
\hline \multirow[t]{3}{*}{ Treatment } & On-demand & 14 & 28.0 & 8 & 16.0 & 6 & 12.0 \\
\hline & Prophylaxis & 31 & 62.0 & 11 & 22.0 & 20 & 40.0 \\
\hline & Both & 5 & 10.0 & 4 & 8.0 & 1 & 2.0 \\
\hline \multicolumn{2}{|l|}{ Total } & 50 & 100 & 23 & 46.0 & 27 & 54.0 \\
\hline
\end{tabular}

Abbreviations: PWH, people with hemophilia; VWD, von Willebrand disease.

Table 3 Time practicing in hemophilia per HCP group $(n=25)$

\begin{tabular}{|l|l|l|l|l|l|l|l|l|}
\hline \multirow{2}{*}{$\begin{array}{l}\text { Duration } \\
\text { in years }\end{array}$} & \multicolumn{2}{|l|}{ All } & \multicolumn{2}{|c|}{ Physician $^{\mathrm{a}}$} & \multicolumn{2}{|c|}{ Nurse $^{\mathrm{a}}$} & \multicolumn{2}{|c|}{ Other } \\
\cline { 2 - 9 } & $N$ & $\%$ & $N$ & $\%$ & $N$ & $\%$ & $N$ & $\%$ \\
\hline $1-5$ & 1 & 4.5 & 0 & 0 & 1 & 25.0 & 0 & 0 \\
\hline $6-10$ & 5 & 22.7 & 3 & 20.0 & 2 & 50.0 & 0 & 0 \\
\hline $11-20$ & 9 & 40.9 & 6 & 40.0 & 1 & 26.0 & 2 & 66.7 \\
\hline$>20$ & 7 & 31.8 & 6 & 40.0 & 0 & 0 & 1 & 33.3 \\
\hline
\end{tabular}

Abbreviation: HCP, healthcare professionals.

${ }^{\mathrm{a}}$ Missing values.

Sixteen percent of HCP worked only with children, $36 \%$ only with adults, and the majority treated both patient groups (48\%). On average, HCP have worked in hemophilia care for $16.5 \pm 7.6$ years, with a range of 2 to 30 years. The majority of physicians have worked in hemophilia care for at least 11 years, whereas the majority of nurses have worked in this area between 6 and 10 years (see - Table 3 ).

\section{Content Validity of the VERITAS-PRO and VERITAS-PRN}

The first group, PWH on prophylaxis $(\boldsymbol{n}=\mathbf{3 6})$, rated two items of the VERITAS-PRO as "very important," which exceeded the $\mathrm{CVR}_{\text {critical }}$ value of $\geq 0.333$. Based on the CVI calculation, one item exceeded the CVI value of $\geq 0.8$ (see -Table 4). None of the items of the domains "Timing," "Planning," "Remembering," and "Skipping" exceeded the $\mathrm{CVR}_{\text {critical }}$ value.

In the second group, PWH with on-demand treatment $(\boldsymbol{n}=\mathbf{1 4})$, three items of the VERITAS-PRN achieved the $\mathrm{CVR}_{\text {critical }}$ value $\geq 0.571$; two items exceeded the CVI value of $\geq 0.8$ (see - Table 4). None of the items of the domains "Treating," "Timing," and "Remembering" exceeded the $\mathrm{CVR}_{\text {critical }}$ value.

The third group, HCP $(\boldsymbol{n}=\mathbf{2 5})$, rated a total of 11 items of the VERITAS-PRO/-PRN as relevant for $P W H$ in the
German healthcare system, thus twice as many items as the PWH: 4 items of the VERITAS-PRO and 7 items of the VERITAS-PRN based on the $\mathrm{CVR}_{\text {critical }}$ value $\geq 0.440$ (see - Table 5). From the VERITAS-PRO, one item each from the domains "Timing," "Dosing," "Planning," and "Communicating" was rated as "very important." From the VERITAS-PRN, three items of the domain "Communicating" with the highest agreement of $\mathrm{CVR}_{\text {critical }}=0.917$ and two items of the domain "Treating" were rated as "very important." Based on the CVI calculation, one item in the VERITASPRO and six items in the VERITAS-PRN exceeded the CVI value of $\geq 0.8$. The items in the domains "Remembering" (VERITAS-PRO, VERITAS-PRN), "Skipping” (VERITAS-PRO), and "Timing" (VERITAS-PRN) were not considered important by HCP.

Overall, only two items of the VERITAS-PRN were considered "very important" by both PWH and HCP according to CVI: "I have enough factor and supplies at home to infuse when needed" belonging to the domain "Planning" and "I call the treatment center before medical interventions, such as dental extractions, colonoscopies, visits to the emergency room, or hospital stays" belonging to the domain "Communicating." Based on $\mathrm{CVR}_{\text {critical }}$, one additional item of the VERITAS-PRO was evaluated "very important" by both groups: "I use the doctor-recommended dose for infusions" belonging to the domain "Dosing."

\section{Suggestions for Additional Items}

Six PWH made in total 14 suggestions for additional adherence questions. The majority of the questions suggested $(n=5)$ were related to factors influencing treatment adherence such as the type of disease or the distance to HTC. The other suggestions were related to aspects such as keeping a substitution diary, visits to and communication with the HTC, documentation of bleeds in smart medication, etc.

Fourteen HCP made in total 24 suggestions for additional items that can be assigned to the following four subject areas: 
Table 4 Items of the VERITAS-PRO and VERITAS-PRN with values of CVI and CVR $>C_{\text {Critical }}$ for PWH with prophylaxis ( $\left.n=36\right)$ and $\mathrm{PWH}$ with on-demand treatment $(n=14)$

\begin{tabular}{|l|l|l|l|l|}
\hline Questionnaires & Domains & Items & CVI & CVR \\
\hline $\begin{array}{l}\text { VERITAS-PRO } \\
\left(\text { CVR }_{\text {critical }} \geq 0.333\right)\end{array}$ & Dosing & $\begin{array}{l}\text { I use the doctor-recommended dose for } \\
\text { infusions }\end{array}$ & 0.833 & 0.667 \\
\cline { 2 - 5 } & Communicating & $\begin{array}{l}\text { I call the treatment center before medical } \\
\text { interventions, such as dental extractions, } \\
\text { colonoscopies, visits to the emergency room, } \\
\text { or hospital stays }\end{array}$ & - & 0.333 \\
\hline $\begin{array}{l}\text { VERITAS-PRN } \\
(\text { CVR }\end{array}$ & Dositical $\geq 0.571)$ & $\begin{array}{l}\text { I use the correct number of factor boxes to total my } \\
\text { recommended dose }\end{array}$ & - & 0.571 \\
\cline { 2 - 6 } & Planning & $\begin{array}{l}\text { I have enough factor and supplies at home to infuse } \\
\text { when needed }\end{array}$ & 0.857 & 0.714 \\
\cline { 2 - 6 } & Communicating & $\begin{array}{l}\text { I call the treatment center before medical } \\
\text { interventions, such as dental extractions, colonos- } \\
\text { copies, visits to the emergency room, or hospital } \\
\text { stays }\end{array}$ & 0.857 & 0.714 \\
\hline
\end{tabular}

Abbreviations: CVI, content validity index; $\mathrm{CVR}_{\text {critical, }}$ critical value of content validity ratio; PWH, people with hemophilia.

(1) documentation behavior $(n=8)$, e.g., "I document my medication after every substitution in smart medication or bleeding diary." (2) Concordance/Compliance $(n=8)$, e.g., "Why do I decide to deviate from the treatment regimen?" (3) Care situation $(n=5)$, e.g., "Is the hemophilia treatment center able to order factor preparations for me within 24 hours?" (4) Competence of the patient for home treatment $(n=3)$, e.g., "Question about ability to interpret bleeding symptoms." In general, HCP criticized that in the VERITASPRO and VERITAS-PRN, items for new forms of treatment for hemophilia were missing.

\section{Discussion}

In total 75 evaluations were available to determine the relevance of the VERITAS-PRO and VERITAS-PRN for hemophilia patients in the German healthcare system, with 50 PWH and $25 \mathrm{HCP}$ assessing the single items according to their importance. To calculate the agreement among $\mathrm{PWH}$ and $\mathrm{HCP}$, the $\mathrm{CVI}^{33}$ and the $\mathrm{CVR}_{\text {critical }}$ based on the table of Ayre and Scally for different numbers of participants ${ }^{37}$ were used.

According to CVI ( $\left.\mathrm{CVR}_{\text {critical }}\right)$, PWH considered three (five) questions as "very important": one (two) item from the

Table 5 Items of the VERITAS-PRO and VERITAS-PRN with values of CVI and CVR $>$ CVR critical for HCP $(n=25)$

\begin{tabular}{|c|c|c|c|c|}
\hline Questionnaires & Domains & Items & CVI & $\mathrm{CVR}_{\text {critical }}$ \\
\hline \multirow[t]{4}{*}{ VERITAS-PRO } & Timing & $\begin{array}{l}\text { I do infusions according to the schedule provided by } \\
\text { the treatment center }\end{array}$ & - & 0.440 \\
\hline & Dosing & I use the doctor-recommended dose for infusions & - & 0.520 \\
\hline & Planning & I plan ahead so I have enough factor at home & - & 0.440 \\
\hline & Communicating & $\begin{array}{l}\text { I call the treatment center when I have questions } \\
\text { about hemophilia or treatment }\end{array}$ & 0.880 & 0.760 \\
\hline \multirow[t]{7}{*}{ VERITAS-PRN } & \multirow[t]{2}{*}{ Treating } & I infuse when there are symptoms of bleeding & 0.880 & 0.760 \\
\hline & & $\begin{array}{l}\text { I follow the guidelines the treatment center has } \\
\text { given me for managing hemophilia }\end{array}$ & - & 0.520 \\
\hline & Dosing & I infuse the prescribed dosage for bleeds & 0.917 & 0.833 \\
\hline & Planning & $\begin{array}{l}\text { I have enough factor and supplies at home to infuse } \\
\text { when needed }\end{array}$ & 0.833 & 0.667 \\
\hline & \multirow[t]{3}{*}{ Communicating } & $\begin{array}{l}\text { I call the treatment center for advice when there are } \\
\text { symptoms of bleeding }\end{array}$ & - & 0.500 \\
\hline & & $\begin{array}{l}\text { I call the treatment center when I cannot tell } \\
\text { whether I need to infuse }\end{array}$ & 0.875 & 0.750 \\
\hline & & $\begin{array}{l}\text { I call the treatment center before medical inter- } \\
\text { ventions, such as dental extractions, colonoscopies, } \\
\text { visits to the emergency room, or hospital stays }\end{array}$ & 0.958 & 0.917 \\
\hline
\end{tabular}

Abbreviations: CVI, content validity index; $\mathrm{CVR}_{\text {critical }}$ critical value of content validity ratio. 
VERITAS-PRO and two (three) items from the VERITAS-PRN, mainly questions in the domains "Dosing," and "Communicating." HCP considered eleven (six) items as "very important": one (four) item from the VERITAS-PRO and five (seven) items from the VERITAS-PRN, mainly questions in the domain "Communicating." Only the items "I have enough factor and supplies at home to infuse when needed" ("Planning") and "I call the treatment center before medical interventions, such as dental extractions, colonoscopies, visits to the emergency room, or hospital stays" ("Communicating") of the VERITAS-PRN and the item "I use the doctor-recommended dose for infusions" ("Dosing") of the VERITAS-PRO were evaluated "very important" by both groups $\left(\mathrm{CVR}_{\text {critical }}\right)$. By contrast the domains "Remembering" (VERITAS-PRO, VERITAS-PRN), "Skipping" (VERITAS-PRO), and "Timing" (VERITAS-PRN) were not considered important by both groups.

\section{CVR/CVI Usage in the Literature}

The application of the CVR and CVI to evaluate the agreement of different raters is widely used in patient-reported outcomes research in medicine. It is mainly applied when a new questionnaire is developed or a validated questionnaire is translated into a new language or when measuring expert consensus.

In 2014, Paneri and Aikat ${ }^{38}$ developed the "Perceived Sexual Distress Scale (PSDS)" in Hindi language (PSDS-H), a questionnaire for persons with spinal cord injuries (SCI). To establish the $\mathrm{CV}$, both qualitative and quantitative (CVR) methods were used. After drafting the 43-item questionnaire, each item was rated by 30 patients with SCI on a 5point Likert scale. Due to too low CVR values, five items were dropped resulting in the final questionnaire with 38 items.

Rodrigues et al developed the "Personalized Exercise Questionnaire (PEQ)" to identify the facilitators, barriers, and preferences to exercise in people with osteoporosis. ${ }^{39} \mathrm{To}$ determine the $\mathrm{CV}$, they too used both the CVI and the CVR. They found that the preliminary version of their 38-item and six-domain scales showed high CV of individual items (I-CVI range: $0.50-1.00$ ) and moderate to high overall $C V$ of the PEQ $(\mathrm{S}-\mathrm{CVI} / \mathrm{UA}=0.63 ; \mathrm{S}-\mathrm{CVI} / \mathrm{Ave}=0.91)$. Through qualitative methods, items could be improved until the PEQ demonstrated high-item CV.

Another development of a PRO measure for health-related priorities of children with Duchenne muscular dystrophy (DMD) used the CVR for testing the CV of the "Muscular Dystrophy Child Health Index of Life with Disabilities (MDCHILD)". ${ }^{40}$ Multidisciplinary HCP completed an itemby-item analysis of the measure and a 14-item sensibility questionnaire. Applying the CVR, Propp et al could show that the MDCHILD met all the sensibility criteria of children with DMD, their parents, and HCP and was ready for psychometric evaluation. ${ }^{40}$

Caruso et al translated the "Dyspnoea-12" for patients with dyspneic syndrome into Italian language. Their aim was to provide a cultural and linguistic validated version. ${ }^{41}$ Ten outpatients rated the clarity of each of the 12 translated items, using a 5-point Likert scale. They used the CVR to assess agreement among raters regarding how pertinent each item was in relation to the objective of its measurement based on a 3-point Likert scale. The authors could demonstrate that all 12 items of the Italian version were relevant.

In another study, the English tool "Champion's Revised Health Belief Model Scale (CRHBMS)" was translated into Persian language and its psychometric properties were assessed. The aim was to assess the validity and reliability of the Persian version of CRHBMS for breast cancer screening among Iranian university students. ${ }^{42}$ After forward/backward translation of the initial 57-item CRHBMS, it was tested by 334 Iranian medical students. Face and content validity of the Persian version was tested using the CVR. After elimination of 15 items, the authors concluded that the Iranian version of the CRHBMS was a feasible tool for evaluating women's health beliefs regarding breast cancer and its screening behaviors.

Seuser et al gathered a panel of five experts in hemophilic arthropathy to evaluate 16 internationally recognized assessment tools for their use in arthropathy. Their aim was to help optimize joint evaluation in $\mathrm{PWH}^{43}{ }^{43}$ The 16 tools were designed to assess structure/function, imaging techniques, activity, participation, objective functional measurements, etc. The authors used two scoring systems: (1) 4point Likert scale ranging from 0 (e.g., no suitability/slow/ difficult) to 3 (e.g., high suitability/rapid/easy) and (2) Yes/ No questions. They used the CVR to measure the consensus between the five experts. They concluded that there was no single joint-function assessment tool that was applicable to all patients and hence there was a need to choose suitable tools based on patients' characteristics and experts' guidance.

\section{Suitability of the VERITAS-PRO/VERITAS-PRN for PWH from the German Healthcare System}

Based on our findings, we concluded that the adherence instruments developed in the United States are less suitable for PWH from the German healthcare system due to some factors influencing adherence and which are different in the U.S. healthcare system compared with Germany. The peculiarities of the U.S. healthcare system, which is primarily based on the market economy rather than on the solidarity principle, contribute to the fact that around 30\% of the U.S. PWH are not or under-insured according to current estimates. ${ }^{44}$ Blankenship illustrated the impact of the five factors influencing adherence previously described by the WHO, using the example of a 13-year-old U.S. patient with hemophilia. The boy weighs $65 \mathrm{~kg}$ and receives a weightdependent dose of 2,720 IU of the coagulation factor three times a week. At a cost of approximately $\$ 1$ per unit, treatment costs of $\$ 1,272,960$ will arise after 3 years. ${ }^{45}$ In the United States, where employees are almost exclusively insured through their employer, there is the so-called lifetime limit of \$1 million, above which health insurance no longer pays any further costs. ${ }^{46}$ For the boy in the example above, this means that the parents would have to look for a new job with another health insurance company after less than 3 years to be able to continue financing their child's treatment. The affected $\mathrm{PWH}$ cannot fund hemophilia 
treatment and therefore have to reduce factor substitution, which negatively affects the average adherence of U.S. PWH. ${ }^{6}$ Since the two adherence instruments VERITAS-PRO and VERITAS-PRN were developed in the context of this overall situation in the United States, ${ }^{23,24}$ we assumed that the VERITAS-PRO and the VERITAS-PRN provide less valid results under German conditions.

A limitation of our study was that the PWH were recruited from only one center, which could have led to a selection bias; on the other hand the participating HCP were from 12 different HTCs all over Germany. In addition, the number of evaluations in the PWH group with on-demand treatment was relatively small, since the CVR and CVI were calculated separately for the current treatment regimens (on-demand treatment: VERITAS-PRN [ $n=14]$, prophylaxis: VERITASPRO $[n=36])$. Based on Ayre and Scally's $C V_{\text {critical, }}{ }^{37}$ the value which must be achieved so that an item is relevant is higher when the number of raters is lower, as it is inversely proportional to the group size.

Although some of the items of the VERITAS-PRO and VERITAS-PRN were considered important, it could be demonstrated that a suitable adherence instrument for $\mathrm{PWH}$ is required for the German healthcare system. In the next step, different focus groups with hemophilia treaters (internists, pediatricians), hemophilia patients (adults, parents of hemophilic children, adolescents with hemophilia) as well as a focus group with representatives of the statutory health insurance companies were performed to assess patient- and physician-relevant aspects for a hemophilia-specific adherence instrument, which will be adequate for the German healthcare system. The results of these focus group surveys will be published separately.

Based on the results of the present evaluation of the adherence questionnaires from the United States, the suggestions for additional items and the focus group results, a hemophilia-specific adherence questionnaire that is adapted to the conditions of the German healthcare system will be developed in a next step.

\section{Conclusion}

According to the evaluations of the $50 \mathrm{PWH}$ and $25 \mathrm{HCP}$ included in our study, VERITAS-PRO and VERITAS-PRN have only limited benefits for the German healthcare system. The critical evaluation of $\mathrm{PWH}$ and $\mathrm{HCP}$ reflects the findings in the literature on cross-cultural validations of both questionnaires, which reveal limitations of their cross-cultural usage due to different aspects: (1) different understandings of linguistic concepts used in the questionnaires, (2) relevance of the single items across different healthcare systems, and (3) problems related to the internal consistency. Since nonadherence has a great impact on the morbidity of PWH and on the costs for the healthcare system, there is a need for adherence instruments that are adapted to the specific needs of PWH in the German healthcare system, which are also able to identify barriers to adherence.

\section{What is known about this topic?}

- Adherence is an important aspect in the treatment of patients with hemophilia (PWH) due to high treatment costs and its impact on the healthcare system-and is also crucial to patients on prophylaxis.

- Therefore, instruments are needed for the adequate measurement of adherence and its barriers.

- Standardized and validated instruments for the assessment of self-rated adherence are available from the United States (VERITAS-PRO, VERITAS-PRN) in 37 languages.

- The VERITAS questionnaires have been used in several international observational studies and clinical trials.

\section{What does this paper add?}

- Differences in the healthcare systems of the United States and Germany have an impact on adherent/nonadherent behavior of PWH.

- Healthcare system-related factors should be taken into consideration when assessing adherence.

- Only few items of the existing U.S. VERITAS questionnaires were rated by patients and healthcare providers as very relevant for the German healthcare system.

- There is a need for an adherence instrument that is adapted to the specific needs of PWH in the German healthcare system, which is also able to identify barriers to adherence.

\section{Authors' Contributions}

Sylvia von Mackensen (S.v.M.) and Susan Halimeh (S.H.) were involved in the planning of the project. S.v.M. analyzed the data; S.H. was involved in patient recruitment. S. v.M. and Yves Douma (Y.D.) wrote the first draft of the manuscript. S.H. reviewed the results and gave relevant input during the review of the manuscript. All authors revised and agreed upon the final version of the manuscript.

\section{Conflict of Interest}

S.v.M. received an unrestricted educational grant from Swedish Orphan Biovitrum Germany to conduct this research. The other authors have nothing to disclose.

\section{Acknowledgment}

The authors would like to thank the hemophilia treaters who were available to evaluate the questionnaires and all PWH who contributed to this work.

\section{References}

1 Sabaté E. Adherence to Long-Term Therapies: Evidence for Action. GenevaWorld Health Organization2003. Available at: https:// www.who.int/chp/knowledge/publications/adherence_Section1. pdf?ua $=1$. Accessed March 30, 2020 
2 Vermeire E, Hearnshaw H, Van Royen P, Denekens J. Patient adherence to treatment: three decades of research. A comprehensive review. J Clin Pharm Ther 2001;26(05):331-342

3 Gordis L. Conceptual and methodologic problems in measuring patient compliance. In: Haynes B, Taylor DW, Sackett DL, eds. Compliance in Health Care. Baltimore, MD: The John Hopkins University Press; 1979:23-45

4 Donovan JL, Blake DR. Patient non-compliance: deviance or reasoned decision-making? Soc Sci Med 1992;34(05):507-513

5 Khair K. Compliance, concordance and adherence: what are we talking about? Haemophilia 2014;20(05):601-603

6 Saxena K. Barriers and perceived limitations to early treatment of hemophilia. J Blood Med 2013;4:49-56

7 Resseguier N, Rosso-Delsemme N, Beltran Anzola A, et al. Determinants of adherence and consequences of the transition from adolescence to adulthood among young people with severe haemophilia (TRANSHEMO): study protocol for a multicentric French national observational cross-sectional study. BMJ Open 2018;8(07):e022409

8 Mannucci PM, Nobili A, Marchesini E, et al. Rate and appropriateness of polypharmacy in older patients with hemophilia compared with age-matched controls. Haemophilia 2018;24(05): 726-732

9 Thornburg CD, Duncan NA. Treatment adherence in hemophilia. Patient Prefer Adherence 2017;11:1677-1686

10 McLaughlin JM, Witkop ML, Lambing A, Anderson TL, Munn J, Tortella B. Better adherence to prescribed treatment regimen is related to less chronic pain among adolescents and young adults with moderate or severe haemophilia. Haemophilia 2014;20(04): 506-512

11 Krishnan S, Vietri J, Furlan R, Duncan N. Adherence to prophylaxis is associated with better outcomes in moderate and severe haemophilia: results of a patient survey. Haemophilia 2015;21(01):64-70

12 Thornburg CD. Physicians' perceptions of adherence to prophylactic clotting factor infusions. Haemophilia 2008;14(01):25-29

13 Miesbach W, Kalnins W. Adherence to prophylactic treatment in patients with haemophilia in Germany. Haemophilia 2016;22 (05):e367-e374

14 Negrier C. The Portal for rare diseases and orphan drugs. Hemophilia 2009. Available at: https://www.orpha.net/consor/cgi-bin/ OC_Exp.php?Lng=EN\&Expert=448. Accessed March 30, 2020

15 Rode J. Rare diseases: Understanding this public health priority. 2005. Available at: https://www.eurordis.org/IMG/pdf/princeps_document-EN.pdf. Accessed March 30, 2020

16 Mannucci PM, Tuddenham EG. The hemophilias-from royal genes to gene therapy. N Engl J Med 2001;344(23):1773-1779

17 O'Hara J, Hughes D, Camp C, Burke T, Carroll L, Diego DG. The cost of severe haemophilia in Europe: the CHESS study. Orphanet J Rare Dis 2017;12(01):106

18 Hacker MR, Geraghty S, Manco-Johnson M. Barriers to compliance with prophylaxis therapy in haemophilia. Haemophilia 2001;7 (04):392-396

19 Anghel LA, Farcas AM, Oprean RN. An overview of the common methods used to measure treatment adherence. Med Pharm Rep 2019;92(02):117-122

20 Guedes VG, Corrente JE, Farrugia A, Thomas S, Wachholz PA, de Oliveira Vidal EI. Comparing objective and self-reported measures of adherence in haemophilia. Haemophilia 2019;25(05):821-830

21 Ho S, Gue D, McIntosh K, Bucevska M, Yang M, Jackson S. An objective method for assessing adherence to prophylaxis in adults with severe haemophilia. Haemophilia 2014;20(01):39-43

22 Lamiani G, Strada I, Mancuso ME, Coppola A, Vegni E, Moja EAProAdherence Study Group. Factors influencing illness representations and perceived adherence in haemophilic patients: a pilot study. Haemophilia 2015;21(05):598-604

23 Duncan N, Kronenberger W, Roberson C, Shapiro A. VERITAS-Pro: a new measure of adherence to prophylactic regimens in haemophilia. Haemophilia 2010;16(02):247-255
24 Duncan NA, Kronenberger WG, Roberson CP, Shapiro AD. VERITAS-PRN: a new measure of adherence to episodic treatment regimens in haemophilia. Haemophilia 2010;16(01):47-53

25 Oldenburg J, Hay CRM, Jiménez-Yuste $V$, et al. Design of a prospective observational study on the effectiveness and realworld usage of recombinant factor VIII Fc (rFVIIIFc) compared with conventional products in haemophilia A: the A-SURE study. BMJ Open 2019;9(05):e028012

26 Di Minno G, Santagostino E, Morfini M, et al. Patient satisfaction and acceptability of an on-demand and on-prophylaxis device for factor VIII delivery in patients with hemophilia A. Patient Prefer Adherence 2019;13:233-240

27 Lock J, Raat H, Duncan N, et al. Adherence to treatment in a Western European paediatric population with haemophilia: reliability and validity of the VERITAS-Pro scale. Haemophilia 2014; 20(05):616-623

28 Cuesta-Barriuso R, Torres-Ortuño A, Galindo-Piñana P, NietoMunuera J, Duncan N, López-Pina JA. Validation of the VERITAS-Pro treatment adherence scale in a Spanish sample population with hemophilia. Patient Prefer Adherence 2017;11:653-660

29 Ferreira AA, Leite ICG, Duncan NA. Validation of the Brazilian version of the VERITAS-Pro scale to assess adherence to prophylactic regimens in hemophilia. Rev Bras Hematol Hemoter 2018; 40(01):18-24

30 Bérubé S, Rondeau É, Sultan S. Measuring adherence in pediatric hemophilia patients: French-language adaptation of the VERITAS-Pro and VERITAS-PRN and psychometric properties. Cogent Med 2019;6(01):

31 Alvi Y, Khalique N, Ahmad A, Khan HS, Faizi N. World Health Organization dimensions of adherence to antiretroviral therapy: a study at Antiretroviral Therapy Centre, Aligarh. Indian J Community Med 2019;44(02):118-124

32 von Mackensen S, Halimeh S. Assessment of adherence in haemophilia patients - evaluation of an US instrument and development of a new questionnaire for use in Germany. HemaSphere 2018;2(01):661

33 Gilbert GE, Prion S. Making sense of methods and measurement: Lawshe's content validity index. Clin Simul Nurs 2016;12:530-531

34 Davis LL. Instrument review: getting the most from your panel of experts. Appl Nurs Res 1992;5:194-197

35 Lawshe $\mathrm{CH}$. A quantitative approach to content validity. Person Psychol 1975;28:563-575

36 Polit DF, Beck CT. The content validity index: are you sure you know what's being reported? Critique and recommendations. Res Nurs Health 2006;29(05):489-497

37 Ayre C, Scally AJ. Critical values for Lawshe's Content Validity Ratio. Revisiting the original methods of calculation. Meas Eval Couns Dev 2014;47(01):79-86

38 Paneri V, Aikat R. Development of the 'Perceived Sexual Distress Scale-Hindi' for measuring sexual distress following spinal cord injury. Spinal Cord 2014;52(09):712-716

39 Rodrigues IB, Adachi JD, Beattie KA, MacDermid JC. Development and validation of a new tool to measure the facilitators, barriers and preferences to exercise in people with osteoporosis. BMC Musculoskelet Disord 2017;18(01):540

40 Propp R, McAdam L, Davis AM, et al. Development and content validation of the Muscular Dystrophy Child Health Index of Life with Disabilities questionnaire for children with Duchenne muscular dystrophy. Dev Med Child Neurol 2019;61(01):75-81

41 Caruso R, Arrigoni C, Groppelli K, et al. Italian version of Dyspnoea-12: cultural-linguistic validation, quantitative and qualitative content validity study. Acta Biomed 2018;88(04):426-434

42 Didarloo A, Akhgar M, Moghaddam-Tabrizi F, Gharaaghaji R, Sheikhi S. Psychometric properties of the Iranian version of Champion's Revised Health Belief Model Scale for Breast Cancer screening. Iran J Nurs Midwifery Res 2020;25(02):146-153

43 Seuser A, Djambas Khayat C, Negrier C, Sabbour A, Heijnen L. Evaluation of early musculoskeletal disease in patients with 
haemophilia: results from an expert consensus. Blood Coagul Fibrinolysis 2018;29(06):509-520

44 Iowa Hemophilia Advisory Committee. Report to the governor and general assembly 2009. 2010. Available at: https://www.legis.iowa. gov/docs/publications/DF/10167.pdf. Accessed March 30, 2020
45 Blankenship CS. To manage costs of hemophilia, patients need more than clotting factor. Biotechnol Healthc 2008;5(04):37-40

46 U.S. Centers for Medicare \& Medicaid Services. Glossary. Lifetime Limit. Available at: https://www.healthcare.gov/glossary/lifetime-limit/. Accessed March 30, 2020 